\section{Marked Reduction of Sacroiliac Joint Inflammation on Magnetic Resonance Imaging in a Patient with Ankylosing Spondylitis After Rituximab Treatment}

\section{To the Editor:}

Rituximab, a chimeric monoclonal antibody directed against CD20 on B cells, is effective to treat rheumatoid arthritis (RA). Reports on the efficacy of rituximab in ankylosing spondylitis (AS) describe good results ${ }^{1,2,3}$, while there is no evidence that active inflammation on magnetic resonance imaging (MRI) in the spine or sacroiliac joints might be suppressed after treatment with rituximab. We describe a patient with AS receiving rituximab who showed improvement in clinical outcomes as well as MRI findings.

A 20-year-old man was diagnosed with AS (HLA-B27-positive) in 2006. He had inflammatory lower back pain, bilateral sacroiliitis (radiological grade II), and left knee arthritis, and did not experience uveitis. His treatment consisted of nonsteroidal antiinflammatory drugs (NSAID) and sulfasalazine, and still he continued to have intermittent lower back pain. In May 2010, he first visited our consultancy due to the persistence of left lumbosacral pain. The Bath Ankylosing Spondylitis Disease Activity Index (BASDAI) score was 2.75, the back pain score (BASDAI question 2) was 8.0 , and the C-reactive protein (CRP) level was $13 \mathrm{mg} / 1$ (normal $<8 \mathrm{mg} / \mathrm{l}$ ). Fat-suppressed T2-weighted MRI scans revealed high signal intensity on the left sacroiliac joint, indicating bone marrow edema (Figure 1A). He was considered to have active AS and received two 500-mg infusions of rituximab with a 2-week interval, together with $40 \mathrm{mg}$ methylprednisolone. He provided signed informed consent for therapy. A clinical response to rituximab occurred when 2 infusions were finished, and since then he has not required NSAID or sulfasalazine. BASDAI score, back pain score, and CRP level decreased to $0.4,1.0$, and $2 \mathrm{mg} / 1$, respectively, 4 weeks after the first infusion and remained low for up to 14 weeks. Finger-to-floor distance declined from $40 \mathrm{~cm}$ at baseline to $0 \mathrm{~cm} 4$ weeks later. In addition, bone marrow edema detected by MRI disappeared almost completely at Week 14 (Figure 1B). Rituximab treatment resulted in a nearly complete depletion of circulating CD19+ B cells (decrease from 284/ $\mu 1$ at baseline to < $10 / \mu 1$ at Week 4 and 14). No adverse events were found during the observation period.
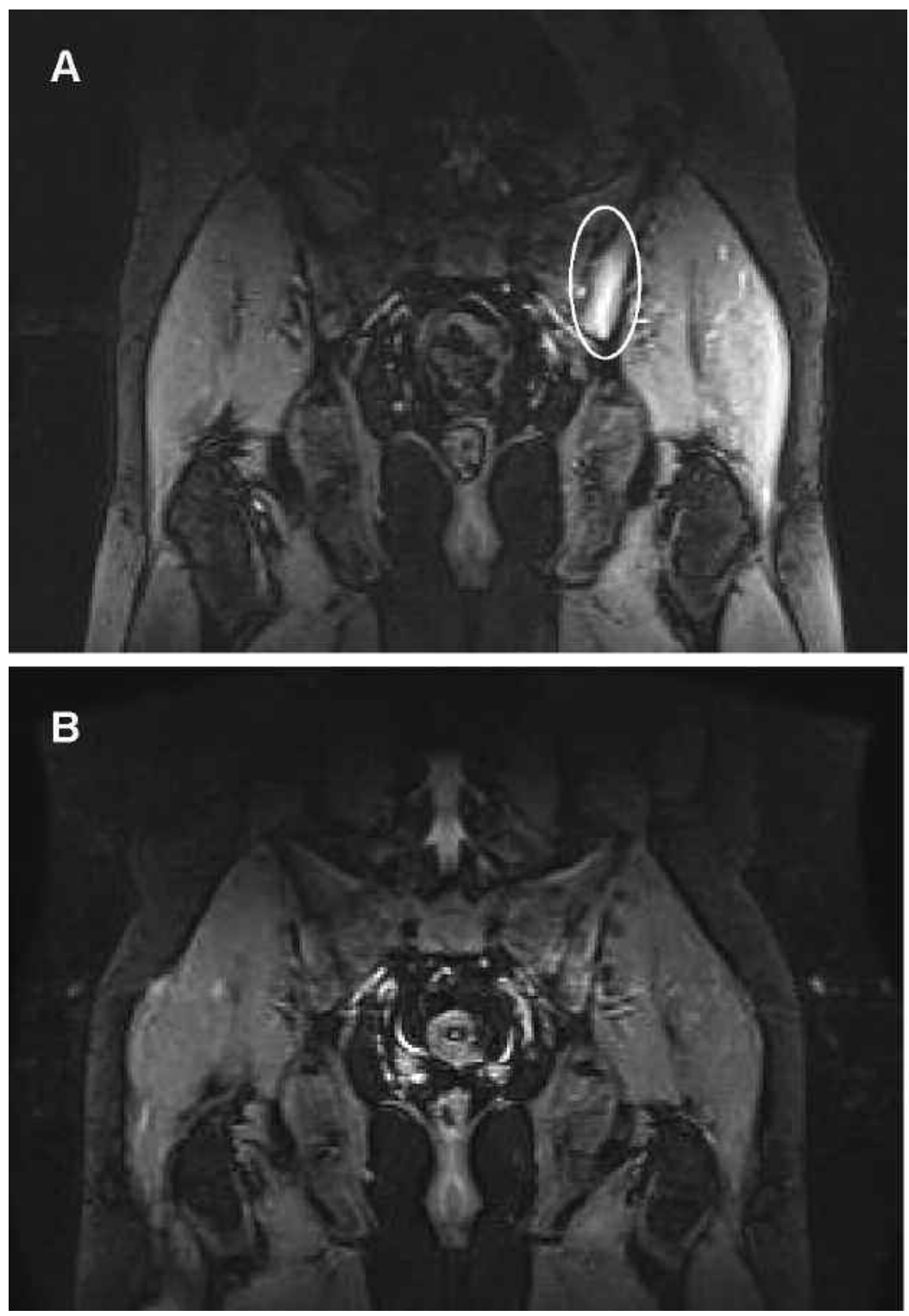

Figure 1. MRI of sacroiliac joints. Left-side sacroiliitis (circle) at baseline (A) and 14 weeks after first rituximab infusion (B). 
Histological studies of spinal specimens from patients with AS have shown B cell clusters in the subchondral bone marrow exhibiting persistent inflammatory lesions, in correlation with MRI findings ${ }^{4,5}$. Therefore, B cell-directed therapies in AS are of interest. The results from a 24-week clinical trial suggest that rituximab treatment $(2 \times 1000 \mathrm{mg})$ has significant efficacy in patients with AS who have never been treated with tumor necrosis factor (TNF) blockers, but not in patients who are nonresponders to TNF blockers, which may explain the conflicting results of case reports ${ }^{1,2,3,6}$. Interestingly, our TNF blocker-naive AS patient responded well to the lower dose of rituximab $(2 \times 500 \mathrm{mg})$. Perhaps the degree of B cell depletion, rather than the rituximab dose, determines clinical response, as reported in $\mathrm{RA}^{7}$. Further, a marked reduction of inflammatory lesion (bone marrow edema) was observed on MRI of the patient's sacroiliac joints 14 weeks after the first rituximab infusion. It is unlikely that this result is associated with the concomitant administration of glucocorticoid because its effect would not have lasted such a long time. In the 24-week clinical trial, no active inflammatory change on MRI was observed at 24 weeks following rituximab treatment and it was thought that the best time for an MRI scan might be earlier, since the highest clinical efficacy was seen at Week 16.

To our knowledge, this is the first description of improvement of active inflammation on MRI after rituximab administration in a patient with active AS. Further controlled studies are needed to evaluate the effect of rituximab treatment on MRI-proven inflammation in patients with AS.

YANG HUANG, MD; FANG CHENG, MD, PhD; XIAOYU ZHANG, MD; JIANPING TANG, MD, PhD, Department of Rheumatology and Immunology, Tongji Hospital, Tongji University, 389 Xincun Road, Shanghai 200065, China.

Address correspondence to Dr. J. Tang;

E-mail: tangjp6568@yahoo.com

\section{REFERENCES}

1. Rodríguez-Escalera C, Fernández-Nebro A. The use of rituximab to treat a patient with ankylosing spondylitis and hepatitis B. Rheumatology 2008;47:1732-3.

2. Song IH, Heldmann F, Rudwaleit M, Listing J, Appel H, Braun J, et al. Different response to rituximab in tumor necrosis factor blocker-naive patients with active ankylosing spondylitis and in patients in whom tumor necrosis factor blockers have failed: a twenty-four-week clinical trial. Arthritis Rheum 2010;62:1290-7.

3. Nocturne G, Dougados M, Constantin A, Richez C, Sellam J, Simon A, et al. Rituximab in the spondyloarthropathies: data of eight patients followed up in the French Autoimmunity and Rituximab (AIR) registry. Ann Rheum Dis 2010;69:471-2.

4. Appel H, Kuhne M, Spiekermann S, Ebhardt H, Grozdanovic Z, Kohler D, et al. Immunohistologic analysis of zygapophyseal joints in patients with ankylosing spondylitis. Arthritis Rheum 2006;54:2845-51.

5. Appel H, Loddenkemper C, Grozdanovic Z, Ebhardt H, Dreimann M, Hempfing A, et al. Correlation of histopathological findings and magnetic resonance imaging in the spine of patients with ankylosing spondylitis. Arthritis Res Ther 2006;8:R143.

6. Wendling D, Augé B, Streit G, Toussirot E, Mathieu S. Lack of short-term efficacy of rituximab upon symptoms of ankylosing spondylitis treated for an associated vasculitis. Joint Bone Spine 2008;75:510-1.

7. Vital EM, Rawstron AC, Dass S, Henshaw K, Madden J, Emery P, et al. Reduced-dose rituximab in rheumatoid arthritis: efficacy depends on degree of B cell depletion. Arthritis Rheum 2011;63:603-8.

J Rheumatol 2011;38:9; doi:10.3899/jrheum.110132 